\title{
EVALUATION OF GENERAL BEHAVIOR, MEMORY, LEARNING PERFORMANCE, AND BRAIN SEXUAL DIFFERENTIATION IN F1 OFFSPRING MALES OF RATS TREATED WITH FLUTAMIDE DURING LATE GESTATION
}

\author{
Kazunori GOTO ${ }^{1}$, Keiji KOIZUMI ${ }^{1}$, Yoshio OHTA ${ }^{1}$, Mariko HASHI ${ }^{1}$, Yoshinobu FUJII ${ }^{1}$, \\ Nanae OHBO $^{1}$, Osamu SAIKA ${ }^{1}$, Hiroetsu SUZUKI ${ }^{2}$, \\ Kenichi SAITO ${ }^{2}$ and Katsushi SUZUKI ${ }^{2}$ \\ ${ }^{I}$ Toxicological Research Department, Odawara Research Center, Nippon Soda Co., Ltd. \\ 345 Takada, Odawara-shi, Kanagawa 250-0280, Japan \\ ${ }^{2}$ Nippon Veterinary and Animal Science University, \\ 1-7-1 Kyonan-cho, Musashino-shi, Tokyo 180-8602, Japan
}

(Received March 15, 2005; Accepted June 6, 2005)

\begin{abstract}
Flutamide is a drug with antiandrogen effects that are mediated through androgen receptors (ARs). In this study, flutamide was subcutaneously administered to female rats $(3,10 \mathrm{or} 30 \mathrm{mg} / \mathrm{kg} /$ day) on gestation Days 16-21 to evaluate effects on memory and learning performance in F1 offspring. Brain sexual differentiation was also evaluated by measuring the volume of the sexual dimorphic nucleus of the preoptic area (SDN-POA) and analyzing levels of androgen receptor (AR) mRNA expression in the prostate, hypothalamus and hippocampus. In F1 offspring exposed in utero to flutamide, evaluation of motor activity, learning performance and spatial perception showed that flutamide tended to exert a dosedependent increase on the motor activity in F1 males, but no significant differences were identified in the other measurements. Prominent changes in development of the SDN-POA were apparent in males after maturation. Doses of $\geq 3 \mathrm{mg} / \mathrm{kg} /$ day resulted in significantly decreased length and volume of the SDNPOA compared to controls. These differences tended to become more marked at higher doses. Volumes of the SDN-POA did not differ significantly between F1 males and females exposed to flutamide at 30 $\mathrm{mg} / \mathrm{kg} /$ day. AR mRNA was assayed using the dot-blotting method in F1 animals. In flutamide dose groups, AR mRNA expression tended to be increased in the prostate gland and decreased in the hippocampus. These results might suggest that exposure to flutamide in utero might affect controlling AR expression on a hormonal signal transduction system mediated by testosterone. However, these changes were not clearly correlated to learning performance in male offspring other than motor activity.
\end{abstract}

KEY WORDS: Flutamide, Anti-androgen, General behavior, Learning performance, Brain sexual differentiation, Rats

\section{INTRODUCTION}

Male hormones such as testosterone play important roles in male reproductive organ development and sexual behavior. Exposure to antiandrogen and estrogen-like substances disrupts normal sex hormone balance in males, thus leading to changes in reproductive organ development and sexual behavior (Sodersten et al., 1975; Gladue and Clemens, 1982; Vagell and McGinnis, 1998). In a study of castrated rats, Gladue and Clemens (1980) reported that flutamide, an androgen receptor (AR) inhibitor, inhibited testosterone-induced sexual behaviors (mounting, intromission and ejaculation). Their findings indicated that testosteronemediated hormonal signal transduction is important in male sexual behavior. In addition, several investigators 
have found that treatment with flutamide in pregnant rats is associated with feminization of sexual characteristics and behavior in offspring (Clemens et al., 1978; Gladue and Clemens, 1978; Brand and Slob, 1991; Vega Matuszczyk and Larsson, 1995).

Differences in not only sexual behavior, but also general behavior patterns and spatial perception between male and female rats have been well documented. Motor activity is greater in females than in males (Schindler and Carmona, 2002), and males display better spatial perception and learning performance (Williams et al., 1990; Joseph et al., 1978). Several studies have reported that exposure to endocrine-disrupting substances during the fetal and neonatal periods can alter normal behavior patterns in males and females. In particular, exposure of males to estrogen-like substances such as bisphenol A and nonylphenol during the neonatal period causes feminization of behavior. In addition, the strong preference for sweets typically seen in females has also been reported in F1 males exposed in utero to polychlorinated biphenyl (PCBs) (Kaya et al., 2002).

In the course of sex differentiation of the brain involved in sexually specific behaviors, steroid hormones during pregnancy and the perinatal periods are well known to be associated with development of the sexual dimorphic nucleus of the preoptic area (SDNPOA) in the hypothalamus (Arai et al., 1996; Rhees et al., 1990; MacLusky and Naftolin, 1981). Dohler et al. (1982) reported that treatment with testosterone to females was exerted on size of the SDN-POA and resulted in almost the same size between females and untreated males. Generally, testosterone binds with ARs in the cytoplasm, forms complexes, and travels to the cell nucleus, where it then binds with DNA to stimulate gene expression (Mooradian et al., 1987; Fang et al., 1969). Anti-androgen flutamide blocks these effects by competitive inhibition of testosterone binding to ARs (Singh et al., 2000; Kumar. et al., 1997). Several studies have shown that in castrated male rats, prostate weight decreases and AR protein mRNA in the prostate increases compared to untreated rats (Shan et al., 1990; Kumar et al., 2002; Kelce et al., 1997). Moreover, Kelce et al. (1997) found that the increase in AR mRNA after castration was blocked by administration of testosterone. Flutamide, a competitive inhibitor of testosterone, leads to similar effects as castration when administered to young animals (Yamada et al., 2000). ARs are also widely expressed in the brain of normal adult males, being most abundant in the hypothalamus, but also found in the hippocampus and cerebral cortex.
This suggests that testosterone displays wide-ranging effects in the brain.

To investigate how an anti-androgen affects general behavior and memory and learning abilities related to the sexually dimorphic brain, the present study evaluated the changes in the brain (SDN-POA size and AR mRNA expression in the hypothalamus and hippocampus) and the sexually specific behavioral patterns in the F1 rat offspring treated with flutamide in utero. In addition to the investigations, AR mRNA expression in the prostate was also evaluated.

\section{MATERIALS AND METHODS}

\section{Experimental animals}

Crj:CD (SD) IGS SPF rats (9-weeks-old) were purchased from Charles River Japan (Atsugi, Japan), and after quarantine for 1 week the animals were employed for study (age at start of mating, 10- to 11weeks-old). Healthy males and females at proestrus, as identified by vaginal smears, were housed together overnight to mate on a 1:1 basis. Next morning, when a sperm-positive smear or vaginal plug was found, the day was designated as gestation day (GD) 0 . Female rats with confirmed pregnancy were randomized based on body weight to treatment groups at the start of the study. Animals were housed individually in stainless steel cages in an animal room with a controlled environment: temperature, $18-24^{\circ} \mathrm{C}$; humidity, $40-80 \%$; and a 12-hr light/dark cycle (light, 0700-1900). During the study, animals were provided access to CA-1 laboratory animal chow (CLEA Japan, Tokyo, Japan) and tap water ad libitum.

Flutamide, obtained from Sigma Chemical Co. (St. Louis, Miss., USA), was dissolved in dimethylsulfoxide (DMSO). DMSO concentration was adjusted to $5 \%$ by adding olive oil to prepare test drug solutions at specified concentrations. Test drug solution was administered at doses of $0,3,10$ and $30 \mathrm{mg} / \mathrm{kg} / \mathrm{day}$, at a volume of $0.5 \mathrm{~mL} / \mathrm{kg}$, once daily on GD 16-21, by subcutaneous injection around the neck. A control group was also established with administration of olive oil and DMSO in a similar manner. Each group comprised 12 females. All pregnant females treated were allowed to deliver spontaneously. On postnatal Day 7, newborn offspring were culled to a total of 12 males and females per litter. After weaning on Days 42-56 (about 7- to 8weeks old), one male and one female from each litter were selected for determination of general behavior, memory and learning performance. For morphological analysis of the SDN-POA, the sexually maturated pups 
Brain sexual differentiation and behavior of rats exposed to flutamide in utero.

that had been examined for general behavior and learning performance were selected. For analysis of AR mRNA expression, the hypothalamus and hippocampus were collected from the 6-week-old male offspring.

\section{Assessment of general behavior, memory and learning performance}

Frequency of locomotion and rearing were measured for one hour using a motor activity system (CompACT; Muromachi Kikai, Tokyo, Japan). Passive avoidance learning was evaluated 3 times in each group over a 3-day period using a passive avoidance response device (Ohara Ika Sangyo, Tokyo, Japan). Spatial learning was tested in the hidden version of the water maze (Morris water maze) on Day 5, after a 4-day training period (learning session). Evaluation included time to reach platform (PF) and false score as calculated from false frequency (not reaching PF) weighed by the number of training days.

\section{Sexual dimorphic nucleus}

F1 rats of 9- to 10-weeks-old were anesthetized using Nembutal ${ }^{\circledast}$ and perfused through the heart at a rate of $10 \mathrm{ml} / \mathrm{min}$ for $10 \mathrm{~min}$ each, first with physiological saline containing heparin (100 units), followed by $10 \%$ neutral buffered formaldehyde. After perfusion and fixation, the brain was removed and sliced coronally in 3-mm sections from the preoptic area to the cerebellum. Tissue was immersed and fixed for at least 4 days in $10 \%$ neutral buffered formaldehyde. Specimens were dehydrated and cleared by standard methods to prepare paraffin blocks. The first $5 \mu \mathrm{m}$ of every $20 \mu \mathrm{m}$ was used for examination. Each section was numbered for identification and stained using Nissl's stain (cresyl violet) for examination. Using the methods of Lund et al. (2000), the area of distribution was then calculated based on the number of slides in each animal showing the SDN-POA. These specimens were examined under stereoscopic microscopy $(\times 7.5$ magnification), and the area was quantified using an image analyzer (Luzex IIIU; Nireco, Tokyo, Japan). Volume was calculated by multiplying the area by $20 \mu \mathrm{m}$ (section interval).

\section{Assay of AR mRNA expression in brain and prostate Preparation of probe}

Total RNA was extracted from the epididymis of untreated adult rats using an RNA extraction kit (RNeasy Mini Kit; Qiagen GmbH, Hilden, Germany). Extracted total RNA was used as a template with oligo-dT primer to synthesize cDNA by reverse transcription. Synthesized cDNA was amplified using polymerase chain reaction (PCR) techniques with oligonucleotide primers A (5'-tcgtctttactaacgtggtaac-3') and B (5'-catctatttccacacacagtga-3') to prepare the AR probes. A synthesized primer corresponding to DNA bases 27313702 was used.

\section{AR mRNA measurement by dot blotting method}

RNA was isolated and purified from tissues of animals in each group using an RNeasy Mini Kit. For quantitative assay of RNA, $10 \mu \mathrm{l}$ of aqueous solution containing the RNA was diluted with $390 \mu$ of distilled water, and absorbance was measured at optimal densities of 260 and $280 \mathrm{~nm}$. Dot blotting was performed with $10 \mu \mathrm{l}$ of each diluted mRNA sample using a nylon positively charged membrane (Hybond-N; Amersham Bioscience, Buckinghamshire, UK). A digoxigenin (DIG)-labeled AR probe was hybridized to each blotted membrane. Using the alkaline phosphatase (ALP)-labeled second antibody method, RNA was quantified according to intensity of the dot on the blotted membrane (DIG High Prime DNA Labeling and Detection Starter Kit 2; Roche, Switzerland).

\section{Statistical analysis}

For parametric continuous variables in the case of multiple groups, Bartlett's test (Bartlett, 1937) was used to analyze differences in variance. If no significant difference $(\mathrm{p} \geq 0.05)$ was identified, Dunnett's test (Dunnett, 1955) was used. If a significant difference $(\mathrm{p}<0.05)$ was present, Steel's test (Steel, 1959) was used for inter-group comparisons. In cases involving 2 groups, Student's $t$-test (Yoshimura, 2003) was used to compare mean values between treatment and control groups. The Wilcoxon rank sum test or Fisher exact test was used to analyze non-continuous variables such as rate of occurrence. Jonckheere trend test was used to evaluate a trend of increase or decrease if necessary. For statistical analysis, $\mathrm{SAS}^{\circledR}$ system v8.2 software (SAS Institute Japan, Tokyo, Japan), JMP ${ }^{\circledR} \mathrm{v} 4.05 \mathrm{~J}$ software (SAS Institute Japan) and Yukms ${ }^{\circledR}$ v2 software (Yuckmus Corp., Tokyo, Japan) were employed.

\section{RESULTS}

\section{Motor activity and frequency of rearing}

In comparison between control males and females, no clear difference was noted. However, the reduced motor activity from $10 \mathrm{~min}$ to $60 \mathrm{~min}$ for males $(2568 \pm 249$; Mean \pm S.D.) was statistically significant as 
higher $(\mathrm{p}<0.05)$ than females $(2018 \pm 660 ;$ Mean \pm S.D. $)$. In addition, mean number of rearings in one $\mathrm{hr}$ tended to be higher in females than in males. Flutamide treatment groups displayed no significant changes in motor activity, although a significant dose-related increasing trend was observed for males and females at $50 \mathrm{~min}$ $(\mathrm{p}<0.05$; Jonckheere trend test). In females, increased trend of rearing frequency was also shown at 10 $(\mathrm{p}<0.05)$ and $50 \min (\mathrm{p}<0.01)$.

\section{Memory and learning performance}

Testing of passive avoidance learning showed no significant differences in males or females in any dose groups as compared to controls (Fig. 2). Comparison between control males and females showed slightly better memory function in males, although the difference was not statistically significant. In the water maze test, no significant changes or constant patterns of
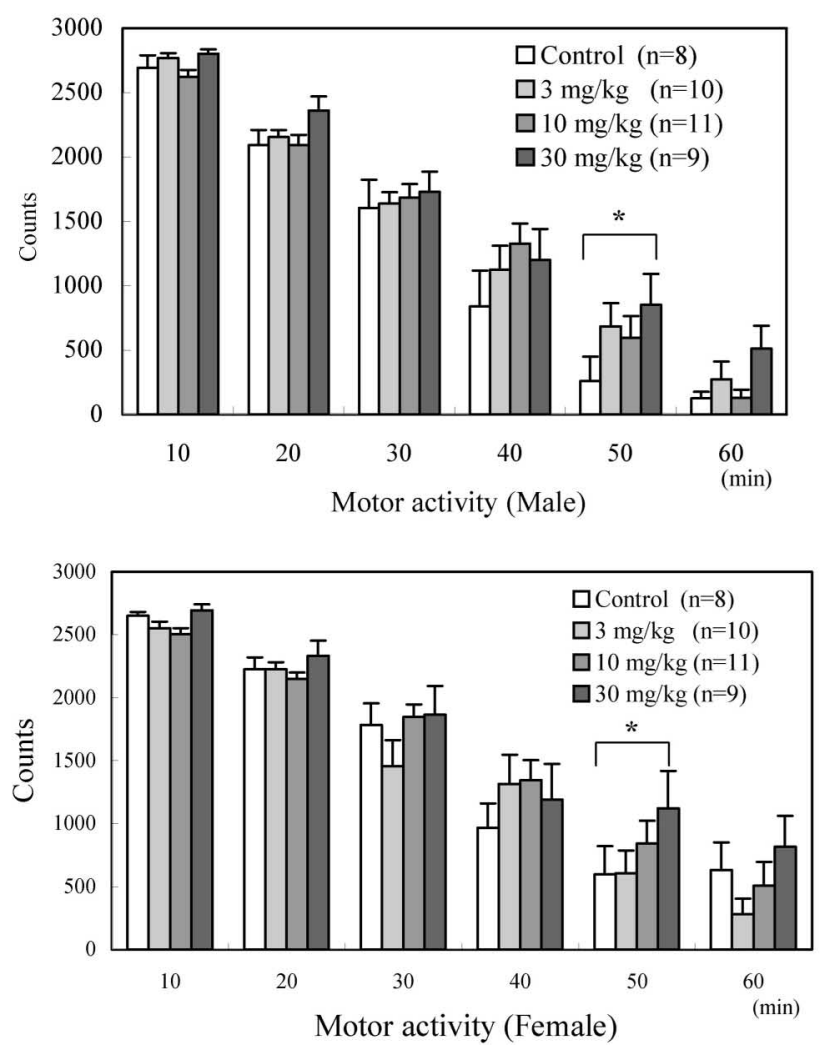

learning performance were noted among the test groups (Fig. 3). Comparison between male and female controls showed slightly better learning performance in males on Day 2 of training, based on number of times to reach PF and number of animals reaching PF, but the difference was not significant.

\section{Sexual dimorphic nucleus}

A clear difference between control males and females in volume of the SDN-POA was confirmed. In flutamide dose groups, volume of the SDN-POA in males was significantly decreased as compared to controls, with a clear dose-related response (Fig. 4). Males at dose of $30 \mathrm{mg} / \mathrm{kg}$ displayed the most prominent decrease in volume, showing no significant difference between females in the same dose group. For females, no significant differences in SDN-POA volumes were identified between any dose groups and control.
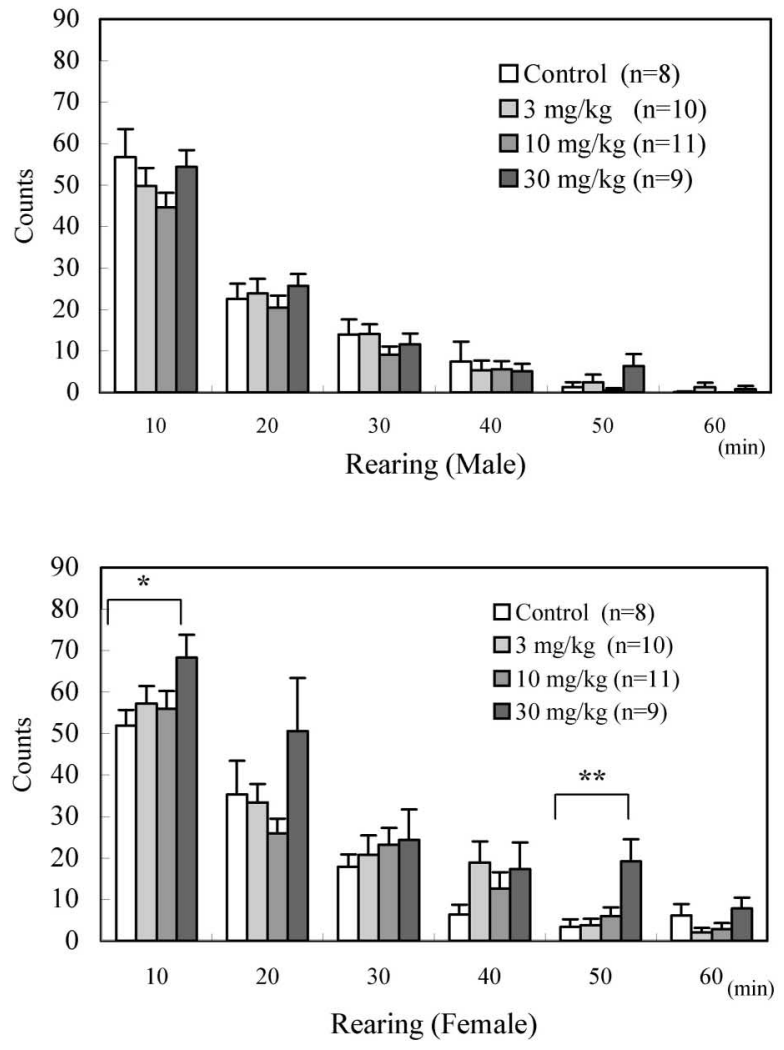

Fig. 1. Effects on motor activity and rearing in $\mathrm{F} 1 \mathrm{offspring}$ exposed to flutamide in utero.

Values show counts of motor activity and rearing for each 10 minute interval and mean \pm S.E.

$\left(* \mathrm{p}<0.05,{ }^{*} \mathrm{p}<0.01\right.$ Jonckheere trend test).

Increased trends of motor activity in males at $50 \mathrm{~min}(\mathrm{p}<0.05)$ and rearing in females at $10(\mathrm{p}<0.05)$ and $50 \mathrm{~min}(\mathrm{p}<0.01)$. were observed. 
Brain sexual differentiation and behavior of rats exposed to flutamide in utero.

\section{AR mRNA expression in brain and prostate}

Electrophoresis of the probe amplified by PCR using primers $\mathrm{A}$ and $\mathrm{B}$ showed a small molecular weight product, at $1033 \mathrm{bp}$ (target product, $966 \mathrm{bp}$ ). The probe was confirmed as the target probe by cutting with a restriction enzyme (EcoR1) at base pairs 1738 2356 (598 bp) and 2356 2709 (353 bp) and comparing with a DNA marker.

\section{AR mRNA in prostate of castrated rats}

AR mRNA in prostate was detected up to a 32fold dilution in castrated rats, compared with a 16-fold dilution in untreated rats, indicating increased AR mRNA expression in castrated rats (Fig. 5).
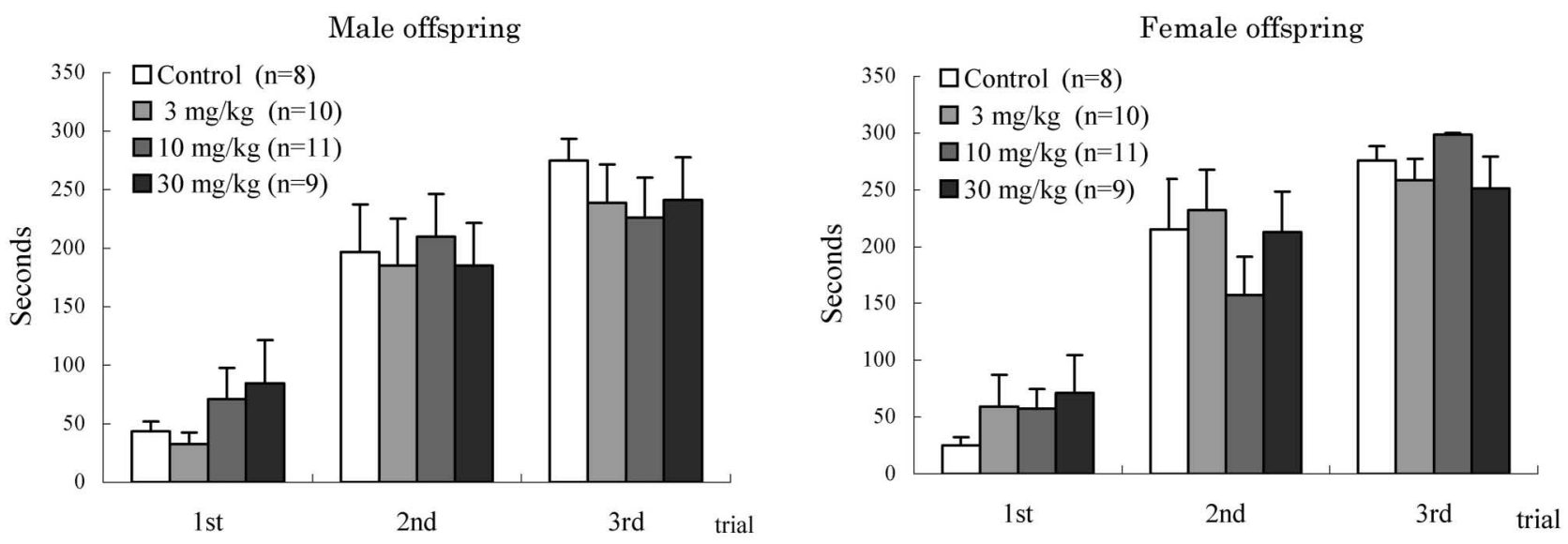

Fig. 2. Results of the passive avoidance test for offspring exposed to flutamide in utero.

Values indicate staying time in the bright room to avoid electric shock in the dark room (Mean \pm S.E.).

Increased time with increasing trials means acquisition of memory by trials in each group. But there were no statistically significant differences among the test groups or sexes.
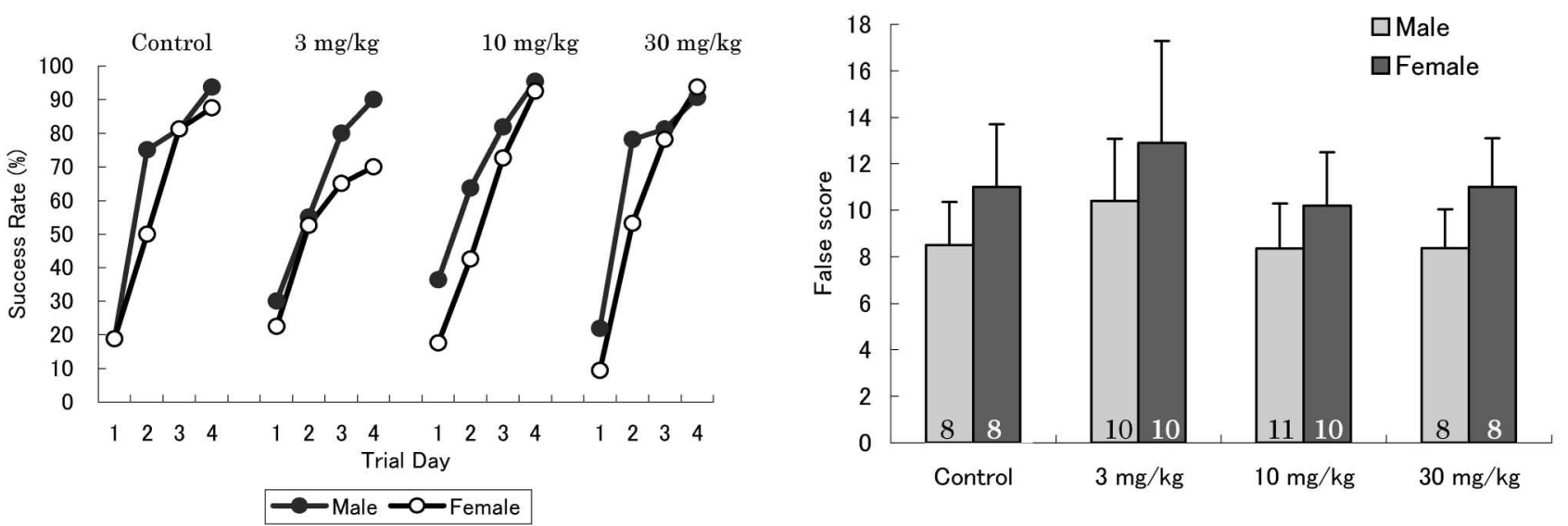

Fig. 3. Results of Morris water maze trial for the offspring exposed to flutamide in utero.

Left: The values (\%) indicate as percent of arriving times to the platform placed in the water pool in each trial. There is no constant pattern among test groups or between males and females.

Right: Mean failure frequency $( \pm$ S.E.) weighed by trial days is shown. Numbers in the bottom of each bar indicate sample size of the measurement. Each false score is calculated in the following formula :

False score $=\Sigma f \times d, f$ : false frequency in each trail day, $d$ : trial days $(1,2,3,4)$

The values show no constant pattern among test groups in each sex. Although the males generally have better results than females, there is no statistically significant difference. 


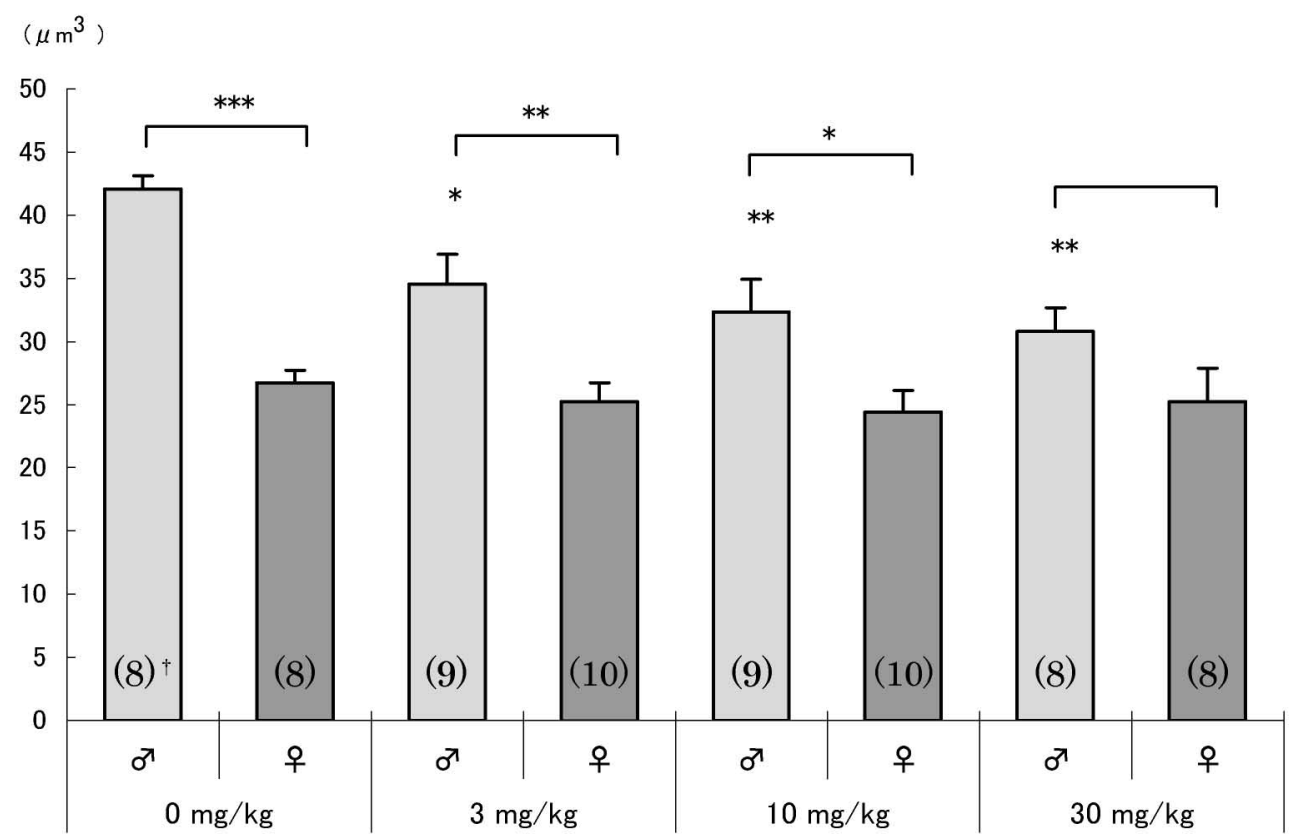

Fig. 4. SDN-POA volume in the preoptic area of the brain from $\mathrm{F} 1$ offspring exposed to flutamide in utero. $(* \mathrm{p}<0.05, * * \mathrm{p}<0.01$. Mean \pm S.E. $)$

${ }^{\dagger}$ Numbers in parenthesis indicate sample size for each group.

The SDN-POA volumes in the male offspring were significantly reduced in the flutamide-treated groups as compared to the control with a dose-related response, but those in the females were comparable in all groups. In difference between males and females, no statistically significant difference was observed at $30 \mathrm{mg} / \mathrm{kg}$. The length of SDN-POA showed the same pattern as the volume (data not shown).

AR mRNA expression level in prostate

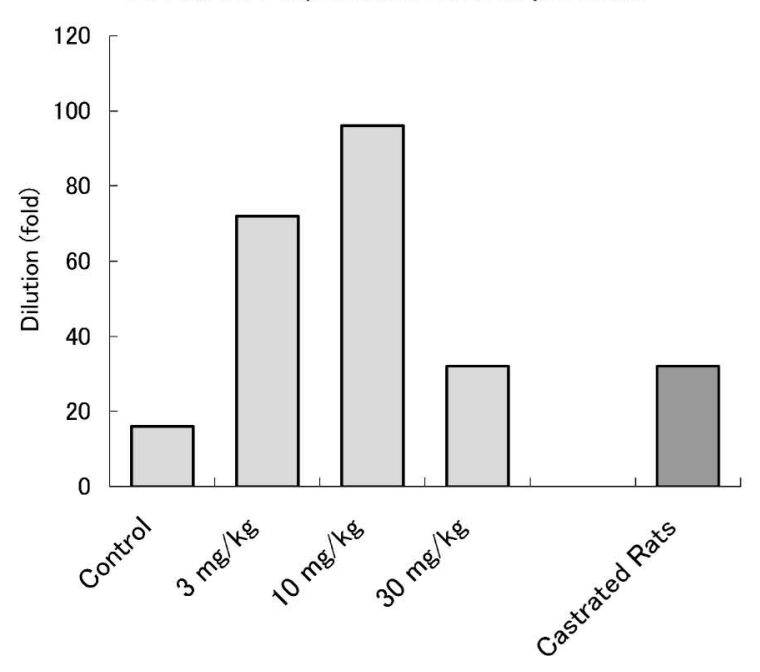

AR mRNA expression in the brain

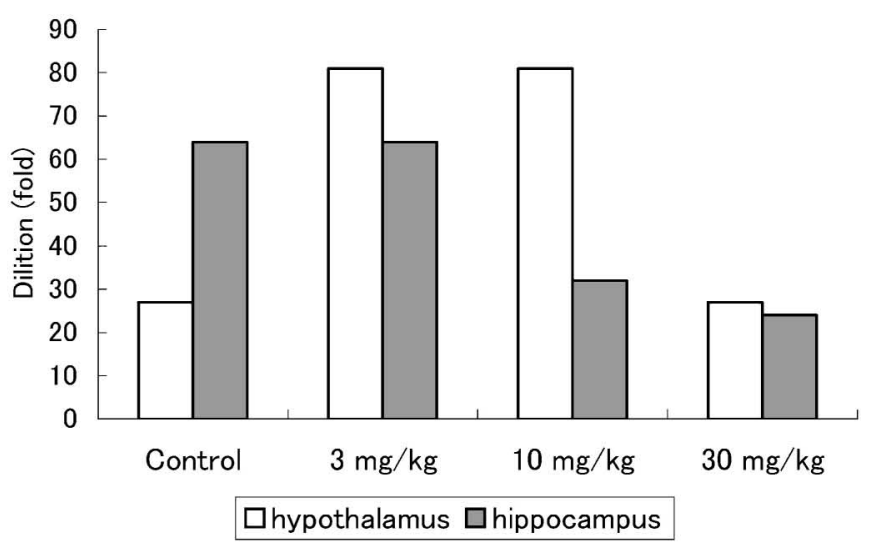

Fig. 5. Androgen receptor (AR) mRNA expression levels in the prostate, hypothalamus and hippocampus of F1 male offspring. The values indicate the maximum dilution level in which the stained dot of mRNA is detectable in the membrane filter by the method of dot blotting. AR mRNA expression in the prostate was increased at 3 and $10 \mathrm{mg} / \mathrm{kg}$, but not clearly increased at $30 \mathrm{mg} /$ $\mathrm{kg}$. Castrated rats showed a slight increase of AR mRNA. In the hippocampus, AR mRNA expression was decreased with dose-related response, but not clear in the hypothalamus, which had a similar pattern to that in the prostate. 
Brain sexual differentiation and behavior of rats exposed to flutamide in utero.

\section{AR mRNA in prostate of flutamide exposed rats}

AR mRNA was assayed in prostate tissue at about 6-months-old in F1 males that had been exposed to flutamide in utero. However, because the prostate was completely defected in several animals at doses of 10 and $30 \mathrm{mg} / \mathrm{kg}$, assays in these groups were performed for only 2 animals and 1 animal, respectively. AR mRNA expression in the atrophied prostate in these dose groups was markedly increased compared to controls (Fig. 5). Prostate AR mRNA expression displayed no dose-related effects, although the number of samples analyzed was limited.

\section{AR mRNA in brain of flutamide exposed rats}

An apparent increase of AR mRNA expression level in the hypothalamus was observed at doses of 3 and $10 \mathrm{mg} / \mathrm{kg}$, but not at $30 \mathrm{mg} / \mathrm{kg}$, which was shown to be comparable to the control (Fig.5). On the other hand, the AR mRNA expression in hippocampus was detectable up to a 64-fold dilution at the control and 3 $\mathrm{mg} / \mathrm{kg}$ groups, 32-fold dilution at dose of $10 \mathrm{mg} / \mathrm{kg}$ and 24-fold dilution at dose of $30 \mathrm{mg} / \mathrm{kg}$, which meant that AR mRNA expression in the hippocampus showed a decrease trend with a dose-related response.

\section{DISCUSSION}

The present study evaluated motor activity as a general behavior and learning performance in F1 offspring rats after exposure in utero to flutamide during late gestation. Motor activity for F1 males tended to be increased in a dose-related manner in flutamide dose groups, but significant differences from control were shown only at $60 \mathrm{~min}$. In general, motor activity has been experimentally shown to be greater in females than in males (Schindler and Carmona, 2002). In the present study, slight sex differences were noted in mean number of rearing for one hour after initiation and in the degree of reduced motor activity from initiation (10 min) to termination $(60 \mathrm{~min})$ of the measurement. Passive avoidance and Morris water maze testing were performed to evaluate learning ability. For the Morris water maze, results were slightly better in males, but no significant sex-differences were observed. In addition, no significant trends in learning or spatial perception ability were noted by flutamide treatment. Sex-related differences in learning ability have previously been reported by other investigators. In a water maze test, Frye (1995) found that a reaching time to PF and a swimming distance in the Morris water maze were significantly longer in estrous females than males, but not in diestrus females. In a study using the radial arm maze and Morris water maze, Roof (1993) observed that males displayed better spatial perception than females. A study with testosterone administration to newborns suggested an important role of testosterone in early development of the brain with respect to spatial perception in males. Meanwhile, Zimmerberg and Farley (1993) evaluated male-female differences in a plus maze and reported superior performance in males. In addition, female and male newborns were chemically castrated with tamoxifen or flutamide, and then similar testing was performed as in surgically castrated animals. No differences were noted between all animals in the plus-maze test. In particular, degree of defeminization was most prominent in females that were chemically or surgically castrated. These results suggest that female hormones play an important role in plus-maze performance. In the present study with flutamide, no significant sex differences were noted, and no clear effects caused by flutamide administration were observed. No significant differences in passive avoidance learning or Morris water maze results were found between males and females in the control and flutamide dosing groups. In utero exposure to flutamide exerted no marked effects on spatial perception in F1 offspring.

Although no effect on brain function was found, in utero exposure to flutamide did significantly affect development of the SDN-POA in F1 males. Length (data not shown) and volume of the SDN-POA was significantly decreased starting at the dose level of 3 $\mathrm{mg} / \mathrm{kg}$, and differences from the control group tended to increase with higher doses. No significant changes occurred in females. Comparing males and females, volume of the SDN-POA was significantly larger in males than in females in the control $(\mathrm{p}<0.01), 3 \mathrm{mg} / \mathrm{kg}$ $(\mathrm{p}<0.01)$ and $10 \mathrm{mg} / \mathrm{kg}$ groups $(\mathrm{p}<0.05)$. However, no significant differences were present between males and females at the dose of $30 \mathrm{mg} / \mathrm{kg}$. These results are consistent with the antiandrogen effects of flutamide and agree with the findings of previous studies (Lund et al., 2000; Rhees et al., 1990). The mechanisms of change impacting volume of the SDN-POA due to flutamide remain unclear, but estrogen and aromatase involved in conversion of testosterone to estrogen play important roles in the brain (Ohe, 1994; Lephart, 1996; Lephart et al., 2001). Tarttelin and Gorski (1991) reported that administration of androgens or estrogens to newborn females increased the volume of the SDN-POA. Feminization of the SDN-POA in male brains with administration of the anti-estrogen tamoxifen was reported by 
Dohler et al. (1984). Treatment of newborn male rats with diethylstilbestrol (DES) caused excessive apoptosis of neurons in the hypothalamus, including the SDN-POA, resulting in decreased volume of the SDNPOA (Nagao, 2003). Androgen exposure in the fetus is thought to inhibit apoptosis of nerve nuclei, including the SDN-POA. In any case, a reduction in volume of the SDN-POA in males is associated with feminization, but the mechanisms have not been clearly elucidated.

To evaluate relationships between androgen and ARs, we first measured AR mRNA expression in the prostate glands of castrated rats. A significant increase was found in AR mRNA levels compared to untreated rats. Our results are similar to those previously reported by Shan et al. (1990) and Kumar et al. (2002). Steinsapir et al. (1991) reported that flutamide inhibited the number of ARs induced by testosterone in adrenalectomized rats, whereas flutamide alone increased AR induction. Androgens and antiandrogen agents such as flutamide are considered to induce synthesis of new ARs, and androgens themselves cause depletion of cytoplasmic and microsomal ARs. Thus, antiandrogens act to inhibit depletion of ARs in microsomes. In other words, antiandrogens are not pure antagonists of androgens, but can also act as agonists in the absence of androgens. Steinsapir et al. (1991) showed that androgens and antiandrogens play a role in the acute regulation of prostate ARs that is mediated by AR protein synthesis. Meanwhile, an investigation of several antiandrogen substances (medroxyprogesterone, chlormadinone acetate, cyproterone acetate, estradiol-17 $\beta$ and flutamide) in castrated male rats by Imai et al. (1990) revealed androgen-like effects for all except flutamide. They recommended further research on the androgen effects of antiandrogen agents.

Kumar et al. (1997) found that a decrease in blood androgen concentrations caused activation of AR genes and up-regulation of AR mRNA. Stimulation of cell proliferation associated with activation of AR genes can lead to development of prostate carcinoma in humans. In the present study, in utero exposure to flutamide during late gestation, as compared to controls, clearly increased prostate AR mRNA in mature F1 offspring. Our results are similar to those in a study by Kumar et al. (1997), in which flutamide administration to non-castrated adult rats decreased prostate weight and markedly increased AR mRNA. In the present study, however, exposure to flutamide was limited to the late fetal period, and measurement of prostate AR mRNA was at $\geq 6$ months postnatal. Thus, no residual flutamide was present in the body at sampling time. In addition, our previous study showed no significant change in serum level of testosterone in flutamide-exposed male offspring as compared to controls (Goto et al., 2004), so the weight loss and histological changes in the prostate are not attributable to decreases in circulating androgen levels. The mechanisms of prostate atrophy and increased expression of AR mRNA observed in our study are therefore likely to differ from the mechanisms of response to flutamide in testosterone-treated and -untreated castrated animals. Injections of testosterone completely reverse castrationinduced alterations in the prostate gland (Dahl, 1976). However, the atrophied prostate of offspring exposed in utero to flutamide can no longer be restored to normal even after testosterone supplementation. Androgens during the fetal and neonatal periods play important roles in sexual differentiation. Treatment with flutamide during late gestation inhibits the action of testosterone, severely affecting not only sexual differentiation in the fetus, but also organogenesis of the sexual organs at maturation in the offspring.

Results of the evaluation of AR mRNA expression in the hypothalamus were inconclusive, but AR mRNA expression in the hippocampus tended to be decreased compared to the prostate. In an evaluation of sex differences in hypothalamic expression of AR mRNA in normal animals, McAbee and Doncarlos (1999) reported higher levels of expression in males at postnatal Day 10. In the present study, however, evaluation at 6-weeks old showed no sex differences in AR mRNA levels. In the same article, McAbee and Doncarlos (1999) found that even with administration of flutamide at doses of $40 \mathrm{mg} / \mathrm{kg} /$ day and $300 \mathrm{mg} / \mathrm{kg} /$ day (p.o.) during the neonatal period, no changes in AR mRNA occurred in the bed nucleus of the stria terminalis or medial preoptic area. In addition, after castration in males on postnatal Day 0, daily administration of DES produced significant increases in AR mRNA in the above areas of the brain, whereas daily administration of dihydrotestosterone propionate caused no changes in AR mRNA. Based on these results, estrogens stimulate and induce brain expression of AR mRNA immediately after birth, but androgens do not exert similar effects. Kerr et al. (1995) found that hypothalamic and hippocampal levels of AR mRNA are similar in untreated mature male rats. They also reported that decreased hippocampal expression of AR mRNA was evidenced in male rats that were administered flutamide (15 mg/animal, s.c.) for 4 days or castrated. However, opposite results in the hypothalamic-preoptic area 
Brain sexual differentiation and behavior of rats exposed to flutamide in utero.

(Burgess and Handa, 1993) and brain (Quarmby et al., 1990) have also been reported. These differences may be attributable to differences in timing of measurements after castration. The continued condition of lowlevel androgens might be associated with increases in AR mRNA. In our study, in utero exposure to flutamide decreased AR mRNA expression in the hippocampus. These results resemble those reported by Kerr et al. (1995). Clearly, post-castration rats are in a "testosterone-free" state, but the mechanisms of the decreased AR mRNA expression involved in our study are different from that in the castrated rats.

In conclusion, in utero exposure to flutamide causes reduced the size of SDN-POA and reduced hippocampal expression of AR mRNA in male offspring, but these changes have no marked influence on specific male-female behavioral patterns in general behavior, memory and learning performance. This may be attributable to the fact that the flutamide exposure was limited to late gestation. Further research should be conducted on the effects of flutamide on behavior in males and females, for example, with longer periods of administration from the late gestation to the postnatal growth period.

\section{REFERENCES}

Arai, Y., Sekine, Y. and Murakami, S. (1996): Estrogen and apoptosis in the developing sexually dimorphic area in female rats. Neurosci. Res., 25, 403-407.

Bartlett, M.S. (1937): Properties of sufficiency and statistical tests. Proc. Roy. Soc., A160, 268-282.

Brand, T. and Slob, A.K. (1991): Perinatal flutamide and mounting and lordosis behavior in adult female Wistar and Sprague-Dawley rats. Behav. Brain Res., 44, 43-51.

Burgess, L.H. and Handa, R.J. (1993): Hormonal regulation of androgen receptor mRNA in the brain and anterior pituitary gland of the male rat. Brain Res. Mol. Brain Res., 19, 31-38.

Clemens, L.G., Gladue, B.A. and Coniglo, L.P. (1978): Prenatal endogenous androgenic influences on masculine sexual behavior and genital morphology in male and female rats. Horm. Behav., 10, 40-53.

Dahl, E. (1976): The ultrastructure of the accessory sex organs of the male rat. XI. Nuclear alterations of prostatic epithelial cells induced by castration. Cell Tissue Res., 171, 285-96.

Dohler, K.D., Coquelin, A., Davis, F. and Hines, M.
(1982): Differentiation of the sexually dimorphic nucleus in the preoptic area of the rat brain is determined by the perinatal hormone environment. Neurosci. Lett., 33, 295-298.

Dohler, K.D., Coquekin, F., Hines, M., Shryne, J.E. and Gorski, R.A. (1984): Pre- and postnatal influence of testosterone propionate and diethylstilbestrol on differentiation of the sexually dimorphic nucleus of the preoptic area in male and female rats. Brain Res., 302, 291-295.

Dunnett, C.W. (1955): A multiple comparison for comparing several treatments with a control. J. Am. Stat. Assoc., 50, 1096-1121.

Fang, S., Anderson, K.M. and Liao, S. (1969): Receptor protein for androgen. On the role of specific proteins in selective retention of 17-beta-hydroxy-5-alpha-androstan-3-one by rat ventral prostate in vivo and in vitro. J. Biol. Chem., 244, 6584-6595.

Frye, C.A. (1995): Estrus-associated decrements in a water maze task are limited to acquisition. Physiol. Behav., 57, 5-14.

Gladue, B.A. and Clemens, L.G. (1978): Androgenic influences on feminine sexual behavior in male and female rats: Defeminization blocked by prenatal androgen treatment. Endocrinology, 103, 1702-1709.

Gladue, B.A. and Clemens, L.G. (1980): Flutamide inhibits testosterone-induced masculine sexual behavior in male and female rats. Endocrinology, 106, 1917-1922.

Gladue, B.A. and Clemens, L.G. (1982): Development of feminine sexual behavior in the rat: androgenic and temporal influences. Physiol. Behav., 29, 263-267.

Goto, K., Koizumi, K., Takaori, H., Fujii, Y., Furuyama, Y., Saika, O., Suzuki, H., Saito, K. and Suzuki, K. (2004): Effects of flutamide on sex maturation and sexual behavior of offspring born to female rats treated during late pregnancy. J. Toxcol. Sci., 29, 517-534.

Imai, K., Watanabe, K., Takahashi, O., Shimizu, N., Nakata, S., Kawashima, K., Suzuki, T. and Yamanaka, H. (1990): [A study of the androgenic activity of anti-androgen] in Japanese. Nippon Naibunpi. Gakkai Zasshi, 66, 597-606.

Joseph, R., Hess, E. and Birecree, S. (1978): Effects of hormone manipulations and exploration on sex differences in maze learning. Behav. Biology, 24, 364-377.

Kaya, H., Hany, J., Fastabend, A., Roth-Harer, A., 
Winneke, G. and Lilienthal, H. (2002): Effects of maternal exposure to reconstituted mixture of polychlorinated biphenyls on sex-dependent behaviors and steroid hormone concentrations in rats: dose-response relationship. Toxicol. Appl. Pharmacol., 178, 71-81.

Kelce, W.R., Lambright, C.R., Gray, L.E. and Roberts, K.P. (1997): Vinclozolin and pp'-DDE alter androgen-dependent gene expression: In vivo confirmation of an androgen receptor-mediated mechanism. Toxicol. Appl. Pharmacol., 142, 192-200.

Kerr, J.E., Allore, R.J., Beck, S.G. and Handa, R.J. (1995): Distribution and hormonal regulation of androgen receptor (AR) and AR messenger ribonucleic acid in the rat hippocampus. Endocrinology, 136, 3213-3221.

Kumar, V.L., Majumder, P.K. and Kumar, V. (1997): Androgen deprivation causes up-regulation of androgen receptor transcript in the rat prostate. Mol. Cell Biochem., 171, 133-138.

Kumar, V.L., Majumder, P.K. and Kumar, V. (2002): In vivo modulation of androgen receptor by androgens. Asian J. Androl., 4, 229-231.

Lephart, E.D. (1996): A review of brain aromatase cytochrome P450. Brain Research Review, 22, 126.

Lephart, E.D., Call, S.B., Rhees, R.W., Jacobson, N.A., Weber, K.S., Bledsoe, J. and Teuscher, C. (2001): Neuroendocrine regulation of sexually dimorphic brain structure and associate sexual behavior in male rats is genetically controlled. Biol. Reprod., 64, 571-578.

Lund, T.D., Salyer, D.L., Fleming, D.E. and Lephart, E.D. (2000): Pre- and postnatal testosterone and flutamide effects on sexually dimorphic nuclei of the rat hypothalamus. Dev. Brain Res., 120, 261-266.

MacLusky, N.J. and Naftolin, F. (1981): Sexual differentiation of the central nervous system. Science, 211, 1294-1303.

McAbee, M.D. and Doncarlos, L.L. (1999): Estrogen, but not androgens, regulates androgen receptor messenger ribonucleic acid expression in the developing male rat forebrain. Endocrinology, 140, 3674-3681.

Mooradian, A.D., Morley, J.E. and Korenman, S.G., (1987): Biological actions androgens. Endocr. Rev., 8, 1-28.

Nagao, T. (2003): Physiological effects of diethylstilbestrol (abstract in Japanese). In Endocrine Dis- ruptor Substances special symposium., pp 4145.

Ohe, E. (1994): [Effects of aromatase inhibitor on sexual differentiation of SDN-POA in rats] in Japanese. Nippon Sanka Fujinka Gakkai Zasshi, 46, 227-234.

Quarmby, V.E., Yarbrough, W.G., Lubahn, D.B., French, F.S. and Wilson, E.M. (1990): Autologous down-regulation of androgen receptor messenger ribonucleic acid. Mol. Endocrinol., 4, 22-28.

Rhees, R.W., Shryne, J.E. and Gorski, R.A. (1990): Onset of the hormone-sensitive perinatal period for sexual differentiation of the sexually dimorphic nucleus of the preoptic area in the female rats. J. Neurobiology, 21, 781-786.

Roof, R.L. (1993): Neonatal exogenous testosterone modifies sex difference in radial arm and Morris water maze performance in prepubescent and adult rats. Behav. Brain Res., 53, 1-10.

Schindler, C.W. and Carmona, G.N. (2002): Effect of dopamine agonists and antagonists on locomotor activity in male and female rats. Pharmacol. Biochem. Behav., 72, 857-863.

Shan, L.X., Rodriguez, M.C. and Janne, O.A. (1990): Regulation of androgen receptor protein and mRNA concentrations by androgens in rat ventral prostate and seminal vesicles and in human hepatoma cells. Mol. Endocrinology, 4, 16361646.

Singh, S.M., Gauthier, S. and Labrie, F. (2000): Androgen receptor antagonists (antiandrogens): Structure-activity relationships. Curr. Med. Chem., 7, 211-247.

Sodersten, P., Gray, G., Damassa, D.A., Smith, E.R. and Davidson, J.M. (1975): Effects of a non-steroidal antiandrogen on sexual behavior and pituitary-gonadal function in the male rat. Endocrinology, 97, 1468-1475.

Steel, R.G.D.(1959): A multiple comparison rank sum test: Treatments versus control. Biometrics, 15, 560-572.

Steinsapir, J., Mora, G. and Muldoon, T.G. (1991): Effects of steroidal and non-steroidal antiandrogens on the androgen binding properties of the rat ventral prostate androgen receptor. Biochim. Biophys. Acta., 1094, 103-112.

Tarttelin, M.F. and Gorski, R.A. (1991): Postnatal influence of diethylstilbestrol on the differentiation of the sexually dimorphic nucleus in the rat is as effective as perinatal treatment. Brain Res., 
Brain sexual differentiation and behavior of rats exposed to flutamide in utero.

456, 271-274.

Vagell, M.E. and McGinnis, M.Y. (1998): The role of gonadal steroid receptor activation in the restoration of sociosexual behavior in adult male rats. Horm. Behav., 33, 163-179.

Vega Matuszczyk, J.V. and Larsson, K. (1995): Sexual preference and feminine and masculine sexual behavior of male rats prenatally exposed to antiandrogen or antiestrogen. Horm. Behav., 29, 191-206.

Williams, C.L., Barnett, A.M. and Meck, W.H. (1990): Organizational effects of early gonadal secretions on sexual differentiation in spatial memo- ry. Behav. Neurosci., 104, 84-97.

Yamada, T., Kunimatsu, T., Sako, H., Yabushita, S., Sukata, T., Okuno, Y. and Matsuo, M. (2000): Comparative evaluation of a 5-day Hershberger assay utilizing mature male rats and a pubertal male for detection of flutamide's antiandrogenic activity. Toxicol. Sci., 53, 289-296.

Yoshimura, I. (2003): In "Statistical Analysis of Toxicological Data", pp. 26-42, Scientist, Tokyo (in Japanese).

Zimmerberg, B. and Farley, M.J. (1993): Sex differences in anxiety behavior in rats: Role of gonadal hormones. Physiol. Behav., 54, 1119-1124. 